\title{
Optimization of Cephalosporin C Acylase Immobilization
}

\author{
Shuangming Tong ${ }^{1,2}$, Linlin Zhu ${ }^{1,2}$, Xiaona Wang ${ }^{3}, \mathrm{Xi} \mathrm{LI}^{3}$, Yanhong Chang ${ }^{1,2,{ }^{*}}$, and Hui Luo ${ }^{3, *}$ \\ ${ }^{1}$ Department of Environmental Engineering, University of Science and Technology Beijing, Beijing 100083, China \\ ${ }^{2}$ Beijing Key Laboratory of Resource-oriented Treatment of Industrial Pollutants, Beijing 100083, China \\ 3. Department of Biological Science and Engineering, University of Science and Technology Beijing, Beijing 100083, China
}

\begin{abstract}
Cephalosporin C Acylase (CCA), the key biocatalyst in one-step enzymatic production of 7amino cephalosporanic acid (7-ACA), was immobilized by amino-activated carrier (LX-1000HA) and epoxy-activated carriers (ES-103B, LX-1000EPC), and the activity was assayed. ES-103B carriers showed an advantage than the others. The amount of free enzyme and salt concentration were tested, and the optimum conditions were 1400U/g and 0.9M. In addition, two different methods (by shaker and packed column) were used in CCA immobilization, and the results demonstrated that the former obtained a higher immobilized CCA activity.
\end{abstract}

\section{Introduction}

Cephalosporins are an important sort of antibiotics that are highly effective, low-toxic and widely used in clinical practice. They become one of the best-selling anti-infective drugs in the world [1]. 7-amino cephalosporanic acid (7-ACA), an important intermediate for the synthesis of cephalosporins, is generally produced through chemical or enzymatic catalyzing cephalosporin C (CPC). The Cephalosporin C Acylase (CCA) is a biological enzyme and capable of directly hydrolyzing the side chain of CPC to produce 7ACA in one step [2]. CCA plays such a significant role in the 7-ACA industrial production, and its applications have developed rapidly in recent years [3]. However, in commercial applications, free enzymes are not available due to its need of strict reaction conditions, poor stability and hard to be reused, then the immobilization process is necessary. The immobilized enzymes are preferred for their high stability, easy separation and reusability [4].

The different immobilization parameters those have an important influence on the activity of the immobilized enzyme, and are of great significance for the application of immobilized enzyme. The purpose of this work is to investigate the immobilization parameters of CCA and obtain excellent performance of immobilized enzyme. Finally, it provides a reference for the industrial production of 7-ACA.

\section{Materials and methods}

\subsection{Chemicals}

CPC and 7-ACA were kindly donated by North China Pharmaceutical Co., Ltd. (Shijiazhuang, China). Epoxyactivated carrier LX-1000EPC and amino-activated carrier LX-1000HA were kindly supplied by Sunresin New Materials Co., Ltd. (Xi'an, China). Epoxy-activated carrier ES-103B was donated by Tianjin Nankai Hecheng Science \& Technology Co., Ltd. All other reagents were of analytical grade.

\subsection{Activation of amino carrier LX-1000HA}

Added $10 \mathrm{~g}$ carrier LX-1000HA to $40 \mathrm{~mL}$ phosphate buffer (PB) of $0.1 \mathrm{~mol} / \mathrm{L}$ and $\mathrm{pH} 8.0$, adjusted $\mathrm{pH}$ to 7.8 8.2 with $1 \mathrm{~mol} / \mathrm{L} \mathrm{NaOH}$, shook at $25^{\circ} \mathrm{C}$ for $15 \mathrm{~min}$, then measured the $\mathrm{pH}$ and adjusted it to 7.8-8.2 again and the above procedure was repeated until the $\mathrm{pH}$ of the solution stabilized at 7.8-8.2 after shaking. After treatment, $10 \mathrm{~g}$ of the carrier was added to $40 \mathrm{~mL}$ of $2 \%$ $(\mathrm{v} / \mathrm{v})$ glutaraldehyde $(0.1 \mathrm{~mol} / \mathrm{L} \mathrm{pH} 8.0 \mathrm{~PB})$, stirred at $25^{\circ} \mathrm{C}$ for $1 \mathrm{~h}$, filtered, and then the carrier was washed three times by deionized water. Due to the low stability of the aldehyde group, the carrier needs to be used immediately after activation.

\subsection{Preparation of the immobilized CCA}

Weighed a certain amount of washed $(0.1 \mathrm{~mol} / \mathrm{L} \mathrm{pH} 8.0$ PB) LX-1000 EPC carrier in a conical flask, added the purified CCA enzyme solution, then $\mathrm{PB}$ of $\mathrm{pH} 8.0$ was added in 2 times the volume of the enzyme solution, and the $\mathrm{pH}$ of the immobilization system was adjusted to 8.0 with $1 \mathrm{~mol} / \mathrm{L} \mathrm{NaOH}$. The suspension was kept under mild stirring in a shaker $(160 \mathrm{rpm})$ for $24 \mathrm{~h}$ at different temperature. Then, the immobilized CCA was recovered by filtration, washed with $\mathrm{PB}(0.1 \mathrm{M}, \mathrm{pH} 8.5)$ and finally stored at $4{ }^{\circ} \mathrm{C}$ until further use. The ES-103B carrier immobilization method was the same as LX-1000EPC carrier. The preparation method of the activated LX1000HA carrier was similar to that of the LX-1000 EPC carrier, just the immobilization time being 20 hours.

\footnotetext{
" Corresponding author: yhchang@ustb.edu.cn (Y. Chang); luohui@ustb.edu.cn (H. Luo)
} 
The immobilization of CCA in a column used the same reagent and physical conditions mentioned above. Carriers were filled in a column, and then the prepared solution (enzyme and buffer) was pumped into the column from the bottom at the flow rate $1.0 \mathrm{~mL} / \mathrm{min}$, the liquid flowing from the top of the column was collected and pumped into the column again. The immobilization time remained the same as it in shaker.

\subsection{Assay of CCA activity}

The enzyme activity of CCA against CPC was measured according to a previously described method with some modifications [5]. A substrate solution was made by dissolving CPC in sodium phosphate buffer $(0.1 \mathrm{M}, \mathrm{pH}$ 8.0 ) at a concentration of $20 \mathrm{~g} / \mathrm{L}$, and the $\mathrm{pH}$ value was adjusted to 8.5 with $1 \mathrm{M} \mathrm{NaOH}$. Next, $20 \mu \mathrm{L}$ CPC solution was mixed with $20 \mu \mathrm{L}$ enzyme solution, and the reaction mixture was then incubated at $37{ }^{\circ} \mathrm{C}$ for $5 \mathrm{~min}$. The reaction was stopped by adding $180 \mu \mathrm{lL}$ termination solution, comprising a mixture of $20 \%(\mathrm{v} / \mathrm{v})$ acetic acid and $0.05 \mathrm{M} \mathrm{NaOH}$ at a $2: 1$ ratio. The reactant was centrifuged at $12,000 \mathrm{rpm}$ for $1 \mathrm{~min}$, and $200 \mu \mathrm{L}$ supernatant was added to $50 \mu \mathrm{L}$ p-dimethylaminobenzaldehyde (dissolved in methanol at a concentration of $0.5 \%$ [w/v]). The colorimetric reaction was carried out at room temperature for $10 \mathrm{~min}$, and the absorbance of samples was measured at a wavelength of $415 \mathrm{~nm}$ against a blank sample containing all the ingredients except enzyme solution. One unit of CCA activity was defined as one micromole of 7-ACA produced per minute at $37^{\circ} \mathrm{C}$ and a $\mathrm{pH}$ of 8.5 .

The activity of the immobilized CCA was determined by weighing about $50 \mathrm{mg}$ biocatalyst beads into a tube containing $4 \mathrm{~mL} \mathrm{CPC}(20 \mathrm{~g} / \mathrm{L})$. The reaction was carried out in a shaking bath at $200 \mathrm{rpm}$ and $37^{\circ} \mathrm{C}$. After $5 \mathrm{~min}$, $20 \mu \mathrm{L}$ of the reactant was collected, and subsequent measurements were carried out as described for the soluble enzyme.

\section{Results and discussion}

\subsection{Immobilization of CCA on different carriers}

In traditional immobilization methods, the covalent bonding method is to covalently bond the inactive side chain group of the enzyme with the reactive functional group in the carrier. The immobilized enzyme exhibits good stability and can be continuously used with high activity, and it has become the most active type of enzyme immobilization method for current application and research. There are many kinds of functional group carriers which can be used for covalently immobilizing enzymes, such as amino groups, epoxy groups, carboxylic acids and so on. Due to the difference in surface groups, polarities of the carrier, the polar groups of the enzymes are also different, and the selectivity of different carriers for enzymes is not always the same, and it is necessary to select a suitable carrier. The ability of immobilized enzyme on various carriers is greatly influenced by the size of the carrier and the size of the pores, and there is a great difference between them [6].

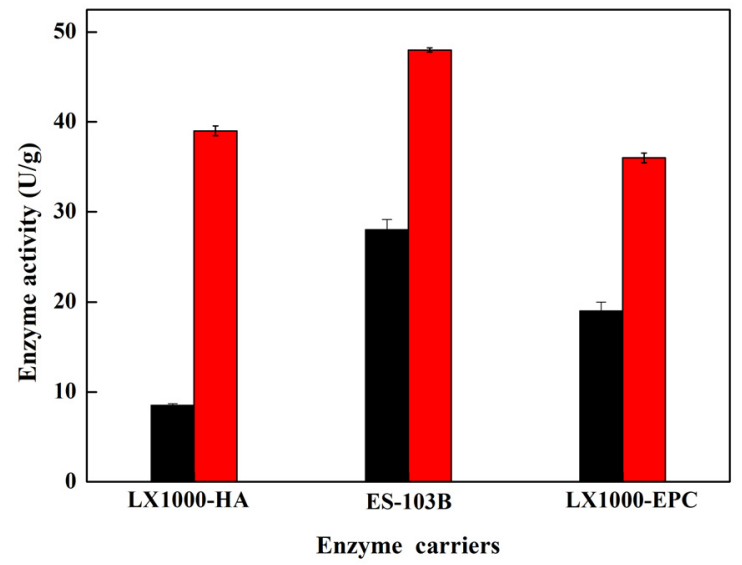

Fig.1. The activity of immobilized CCA by different carriers at immobilization temperature of $25^{\circ} \mathrm{C}(\boldsymbol{u})$ and $12^{\circ} \mathrm{C}(\boldsymbol{a})$

In this work, the enzymatic activity of immobilized CCA prepared by using epoxy carrier LX-1000EPC, ES$103 \mathrm{~B}$, and amino carrier LX-1000HA at temperatures of $12^{\circ} \mathrm{C}$ and $25^{\circ} \mathrm{C}$ was investigated. $12{ }^{\circ} \mathrm{C}$ was chosen because it was used in some industrial applications. The activity of immobilized CCA with enzyme concentration of $400 \mathrm{U} / \mathrm{g}$ using the epoxy carrier-based ES-103B, LX$1000 \mathrm{EPC}$ and amino carrier LX-1000HA at preparing temperature of $25{ }^{\circ} \mathrm{C}$ and $12{ }^{\circ} \mathrm{C}$ is shown in Fig. 1. As can be seen from Fig. 1, the immobilized enzyme activity with different carriers was quite different, whether it was at $12^{\circ} \mathrm{C}$ or $25^{\circ} \mathrm{C}$. Therefore, it is necessary to select a suitable immobilization carrier for immobilization of a specific enzyme. For CCA, it is clear that the epoxy-activated carriers were more suitable than amino-activated carrier. Specially, the ES-103B carrier had a greater advantage than other carriers. Hence, the ES-103B carrier was considered as a model carrier for subsequent investigation.

\subsection{Effects of the free enzyme amount on the activity of immobilized CCA}

When the carrier adsorbs free enzyme, the adsorption rates are different with the various free enzyme amount added in the immobilization process, and then the performances of immobilized enzymes were also different [7]. Therefore, it is of great significance to optimize the adding free enzyme amount. In this paper, the enzyme amount of 100, 200, 400, 800, 1200, 1400, and $1600 \mathrm{U} / \mathrm{g}$ were selected to study the effect of free enzyme dosage on the immobilization of CCA by epoxybased ES-103B carrier. Fig. 2 displayed the effects of the free enzyme amount on the activity of immobilized CCA. As can be seen from Fig. 2, as the amount of the free enzyme was increased from low, the enzyme activity of ES-103B carrier immobilized enzyme was continuously increased, because of the amount of the enzyme bound in the unit mass of the carrier being more. With increasing addition of the free CCA, the enzyme that had been bound to the carrier would occupy the corresponding site on the carrier, so that the newly added enzyme molecule could not bind to the active group on the surface of the 
carrier. Even if some enzymes were immobilized in the internal pores, which was difficult to play a role in the reaction [8]. In addition, for a certain amount of immobilized carrier, it had a certain load capacity. And when the amount of the enzyme was increased to a certain extent, the enzyme molecule was difficult to effectively combine with the carrier.

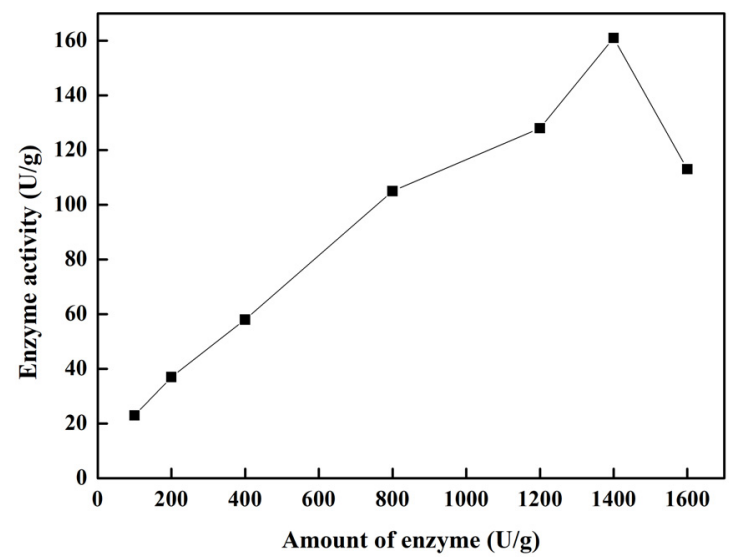

Fig. 2. The activity of immobilized CCA with different amount of free enzyme

For the ES-103B carrier, the immobilized enzyme activity reached a maximum with $1400 \mathrm{U} / \mathrm{g}$. The reason may be that the immobilization of CCA on the epoxy group carrier involved two steps, firstly a rapid and gentle physical adsorption, followed by a slow covalent reaction between the adsorbed enzyme and the carrier epoxy group when the amount of the enzyme was increased, which reduced the contact area of the enzyme with the carrier, affected the efficiency of physical adsorption, and reduced the activity of the immobilized enzyme. Therefore, according to the immobilized enzyme activity, the optimal enzyme amount of the ES103B carrier was $1400 \mathrm{U} / \mathrm{g}$.

\subsection{Effects of the salt concentration on the activity of immobilized CCA}

Due to the difference in polarity of the carrier, hydrophilicity and hydrophobicity, the salt concentration has different effects on the immobilization of different carriers and enzymes, which will affect the process of the enzyme approaching the carrier [9]. CCA was immobilized by different concentrations of phosphate solution $(0.6,0.7,0.8,0.9,1.0$, and $1.1 \mathrm{M})$ to investigate the effect of salt concentration on the ES-103B carrier immobilization. From the Fig. 3, it can be seen that as the salt concentration increased, the enzyme activity of the prepared immobilized enzyme also increased; and when the salt concentration was greater than $0.9 \mathrm{M}$, the enzyme activity showed little change. The reason may be that the salt concentration had a promoting effect on the enzyme approaching to the carrier. The higher the salt concentration, the stronger the promoting effect; but when the enzyme was enough easy to close to the carrier the by promoting effect, which resulted in the enzyme approaching the carrier being no longer the constraints of immobilization, so further increase of concentration was not effective.

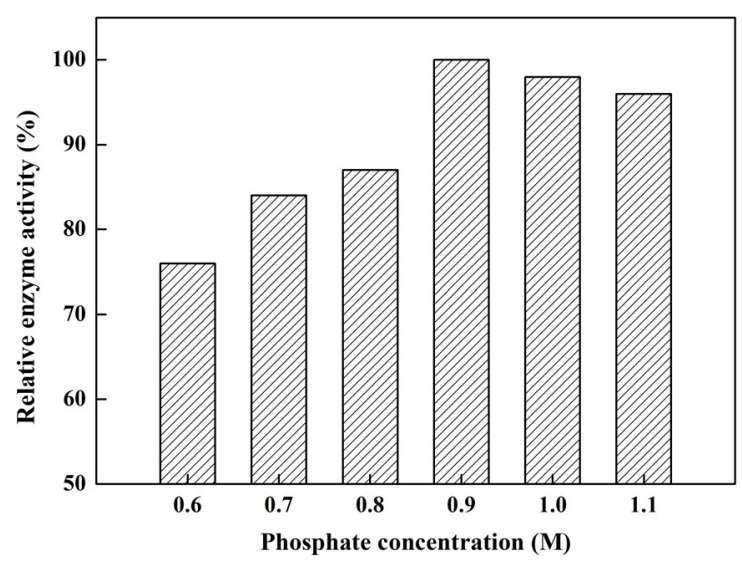

Fig. 3. The relative activity of immobilized CCA with different salt concentration

It can be found that $0.9 \mathrm{M}$ was the optimum salt concentration for immobilization and further optimization.

\subsection{Immobilization of CCA through different methods}

There are two kinds of methods for the enzyme immobilization. One is the common oscillation immobilization, which is the enzyme solution being mixed with the carrier and uniformly shaken in a shaker. Another is to tightly fill the carrier in the column, and the enzyme is pumped through the column from one end to the other with certain flow rate. During the shaking immobilization process, the carrier and the enzyme solution are uniformly mixed. At the same time, the target protein in the enzyme solution is in full contact with the carrier. The target protein surrounds the periphery carrier, and the enzyme solution forms a concentration difference in the carrier channel, thereby the target protein in the enzyme solution is fixed into the pores by diffusion due to the concentration gradiant [10]. In the column immobilization, the enzyme solution passes through the fixed column filled with the carrier at certain flow rate, and the immobilization of target protein in the enzyme solution depends not only on the concentration difference but also on the external force from the flow rate.

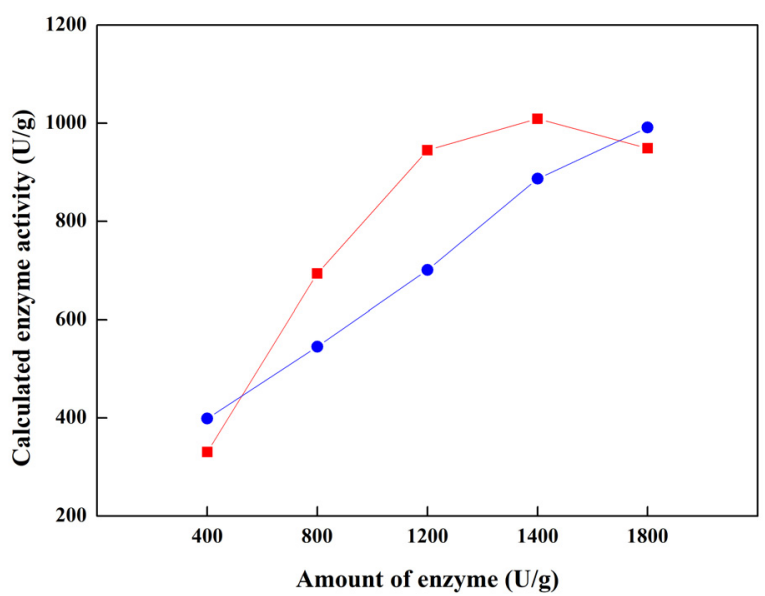

Fig. 4. The calculated activity of immobilized CCA by shaker $(-\square-)$ and column $(-\diamond-)$ 
In order to investigate the immobilization ability of different immobilization methods, the amount of enzyme immobilized on the carrier was calculated. The amount of enzyme added before immobilization subtracted the enzyme remained in the solution after immobilization per gram carrier was calculated enzyme activity. Fig. 4 displays that the immobilized enzymes by two immobilization methods had significant differences. When the enzyme amount was below $1400 \mathrm{U} / \mathrm{g}$, the calculated immobilized enzyme activity obtained from oscillation method was higher than the column immobilization, however, when the amount enzyme increased further, the situation became different. The enzyme activity of the oscillation was reduced, while the column-fixed enzyme activity was still increased, as a result, the activity obtained in column surpassed that in the shaker. That can be attributed that the enzyme solution was in full contact with the carrier during the shaking immobilization process, but the enzyme solution was only partially in contact with the carrier in the column immobilization process. When the enzyme solution flowed in one direction, the target protein was immobilized in one hemisphere mostly and fewer target protein was immobilized in the other hemisphere. When the amount of enzyme increased, in the column immobilization process, the target protein could enter deeply into the carrier channel with the external force from the pump, and the enzyme activity and protein amount immobilized by the column immobilization method could be further improved. Comparatively, because enzyme immobilization in shaker was simple and the higher enzyme activity, it had advantages over the column type.

\section{Conclusions}

The immobilization of CCA by an epoxy-activated carrier was advantageous over that by amino-activated carrier, both at low temperatures and high temperatures, including ease of immobilization and higher enzymatic activity. Relatively, ES-103B was more efficient. The amount of enzyme and the salt concentration in the immobilization were important parameters, which were $1400 \mathrm{U} / \mathrm{g}$ and $0.9 \mathrm{M}$, respectively. The oscillating immobilization had advantages over the column type, and its operation was simple and the enzyme activity was higher.

\section{Acknowledgements}

This work was supported by the National Science Foundation of China (21476025). The authors have no conflict of interest to declare.

\section{References}

1. Sader H S, Jacobs M R, Fritsche T R. Diagnostic microbiology and infectious disease, 2007, 57(3): S5-S12.
2. Pollegioni L, Rosini E, Molla G. Applied microbiology and biotechnology, 2013, 97(6): 23412355.

3. Kim D W, Yoon K H. Biotechnology letters, 2001, 23(13): 1067-1071.

4. López-Gallego F, Fernandez-Lorente G, RochaMartin J, et al. Immobilization of Enzymes and Cells: Third Edition, 2013: 59-71.

5. Patett F, Fischer L. Analytical biochemistry, 2006, 350(2): 304-306.

6. Khan A A, Akhtar S, Husain Q. Journal of Molecular Catalysis B Enzymatic, 2006, 40(1): 5863.

7. Golden E, Paterson R, Tie W J, et al. Biochemical Journal, 2013, 451(2): 217-226.

8. Wang $\mathrm{Y}$, Nor $\mathrm{Y}$ A, Song $\mathrm{H}$, et al. Journal of Materials Chemistry B, 2016, 4(15): 2646-2653.

9. Caterina Boniello, Torsten Mayr, Ingo Klimant, et al. biotechnology and bioengineering, 2010, $106: 4$.

10. Caterina Boniello, Torsten Mayr, Juan M Bolivar. BMC Biotechnology, 2012, 12:11 